\title{
Editorial
}

\section{Valuing Antarctic science}

$\mathrm{L}$ ooking backwards should always be instructive. The lessons that history can teach us are, of course, fundamental to progress in science but what about its management?

Science is changing worldwide, driven at least in part by the enthusiastic application of "market principles" by governments. To many politicians science is about products. A good example of this is the new focus in Britain on assessment of each grant application for its potential contribution to "wealth creation" and the "quality of life". The application of science through technology and environmental management delivers useful products and these can be taken as proxies for the value of science. Yet in many ways good science is like good art - forever experimenting, always in need of new ideas, inspirational, unpredictable. Should we then test art funding in the same way as science?

This is not the digression it may seem. Competition for limited funds means that science has to justify itself or lose its funding. In management jargon - which output indicators show efficiency, effectiveness and value for money in terms that government will accept? In the high cost area of Antarctic science we can ill-afford not to give this our closest attention. We need to address two problems - the absolute allocations to Antarctic research and the relative allocations of resources to disciplines within that.

Many countries use some form of peer and merit review to assess the scientific value of individual project proposals. That should recognize good science within the discipline, but who decides - and how - that the best ideas in climatology are better than the best ideas in marine biology or that tropical forests are more important than Antarctic glaciology? In questioning the allocation of funds within science, in setting objectives and insisting on "relevance assessments", in whatever forms, governments are forcing us to face up to these difficult questions. Ignoring them will not make them go away.

Science is not all equally costly so that output (in terms of papers published) could be manipulated by moving funds from say geophysics to biology. Unfortunately cheapness alone is not a useful indicator of the value of science - although it might be hard to convince the Treasury of that! One of the easiest ways to allocate budgets is on the historical principle - you get the same proportion this year as you did last year. But this takes no account of changes in priorities or in actual costs. The costs of undertaking particular fields of science change - for example, moving from traditional taxonomy to molecular taxonomy is likely to put up costs by an order of magnitude. From this we must conclude that allocations should be dynamic and methods need to be incorporated into each national system to provide the "apples and pears" comparisons which could, for example, result in cutting geology to fund climate modelling.

So how can we impartially subdivide existing funds to reflect merit, importance, relevance and similar key criteria? There is no foolproof system which does not involve non-quantifiable human judgement as a key arbiter but in addressing these criteria for each research proposal it often becomes clear which proposals are scientifically most interesting and best fit the other criteria. Slavish adherence to citation assessments and other mechanistic valuations can never provide the balanced judgement needed in deciding which science is most valuable at a particular point in time.

There will never be enough money to do everything we want to do but it will certainly not benefit science progress in general if decision making is left to accountants and politicians. Antarctic science is globally relevant. Let's make sure that is even more clearly recognized in the future when science assessments are made and when resources are partitioned. It should go without saying that only good science should be funded both in the Antarctic and elsewhere.

D W H WaLton 